\title{
Effect of direct air injection through anode in plasma electrolysis process for batik dye wastewater treatment
}

\author{
Nelson Saksono ${ }^{1, *}$, Tulus Sukreni ${ }^{1}$, Apryani Lestari Naibaho ${ }^{1}$, Setijo Bismo ${ }^{1}$ \\ ${ }^{1}$ Chemical Engineering Department, Faculty of Engineering, Universitas Indonesia, Indonesia, Depok 16424, Indonesia
}

\begin{abstract}
Plasma electrolysis has been proved have much higher effectivity in degrading complex pollutant contained in batik dye wastewater. This study aims to investigate the effect of gas bubbles with air injection of plasma electrolysis in decolorization process. A new method to form bubbles using injection of air directly through anode with a tiny hole of glass tube is proposed. This research work presents the effects of gas injection rates on various phenomena such as electrical power of discharge pulses, concentration of $\mathrm{OH}$ radicals, and the decolorization percentage of remazol red as the dye waste in a batch reactor system. Experimental results showed that direct injection of air through anode can reduce the required energy for plasma generation significantly compared to non gas injection. Energy consumption for discharge plasma was observed lowered at higher rates of gas injected. Optimum gas flow rate at different voltage has been evaluated based on the physical and chemical characteristics of plasma. At higher required energy due to higher operation voltage used, the required gas injection rate to effectively degrade the waste was found higher.
\end{abstract}

\section{Introduction}

Azo dyes are the most widely used in the batik industry since those dyes have several advantages such as high economic value, easy to obtain, resistant to various environmental conditions and have wide color range. However, azo dyes are strong biological toxic and have complex aromatic structure resulting in the difficult degradation for the liquid waste. Several treatment processes such as biological, physical, and chemical treatements have been used to degrade color molecules from batik waste, but each one has some shortcomings in terms of time, equipment, and cost. However, several studies have shown that plasma electrolysis method is effective and efficient in degrading the waste both in terms of the percentage of decolorization and processing time.

The plasma produced during the plasma electrolysis process, occurs at sufficiently high operating voltage which exceed the breakdown voltage. The heat generated can forms a layer of gas sheath around the electrode and then forms the plasma [1]. The process requires a large energy consumption caused by the high dielectric strength of the liquid. The gas injection is used to form bubbles and the gas sheath layers to assist plasma formation which has proved to significantly reduce the energy consumption. This is due to the smaller dielectric strength of the gas compared to the liquid [2]. The addition of gas injection can also reduce the erosion of the electrodes where the plasma is formed. In addition, gas injection may affect the formation of active species where the gas type, gas injection flow rate, and injection mechanism affect the physical and chemical characteristics of the plasma formed [3]. Plasma electrolysis can form several active species such as $\mathrm{H}^{+}$, $\mathrm{H}_{3} \mathrm{O}^{+}, \mathrm{H}^{-}$, reactive radicals such as $\mathrm{OH}$, as well as molecular species such as $\mathrm{H}_{2}$ dan $\mathrm{H}_{2} \mathrm{O}_{2}$ [2-3]. All of these active chemical species can attack and then degrade various pollutants contained in the waste.

This study explains the effect of flow rate of air injection and operating voltage on energy consumption during the process of plasma formation, $\mathrm{OH}$ radical concentration and the percentage of decolorization of batik dye waste.

\section{Material and Method}

The scheme of batch reactors of $130 \mathrm{~mm}$ in diameter and $190 \mathrm{~mm}$ in height used for this study is shown in Figure1.

Plasma electrolysis reactor is made from transparent glass equipped with electrode and cooling water circulation. The electrodes used are stainless steel with diameter $6 \mathrm{~mm}$ for cathode and tungsten with diameter $0.5 \mathrm{~mm}$ for anode. The anode was covered with a glass tube by the hole as the entrance and exit of air injected into the reactor (Figure 2).

The flow rate of the gas was varied to $01 / \mathrm{min}$ (nongas injection), $0.3 \mathrm{l} / \mathrm{min}, 0.5 \mathrm{l} / \mathrm{min}, 2 \mathrm{l} / \mathrm{min}, 4 \mathrm{l} / \mathrm{min}$, and $6 \mathrm{l} / \mathrm{min}$. The operating voltage required to generate the plasma is varied to $500 \mathrm{~V}, 600 \mathrm{~V}$, and $700 \mathrm{~V}$. The controlled process temperature was $50-55^{\circ} \mathrm{C}$ and each process sequence was carried out in 30 minutes, for $\mathrm{OH}$ radical measurements, energy consumption and

\footnotetext{
Corresponding author: nelson@che.ui.ac.id
} 
decolorization process. Measurement of $\mathrm{OH}$ radicals using permanganometry titration method with $\mathrm{KMnO}_{4}$ $0.01 \mathrm{~N}$. Standardization of $\mathrm{KMnO}_{4}$ solution before measurement was done using $\mathrm{Na}_{2} \mathrm{C}_{2} \mathrm{O}_{4} 0.01 \mathrm{~N}$ solution. Titrations with the addition of $\mathrm{H}_{2} \mathrm{SO}_{4} 10 \mathrm{M}$ were performed at temperatures $80-85^{\circ} \mathrm{C}$.

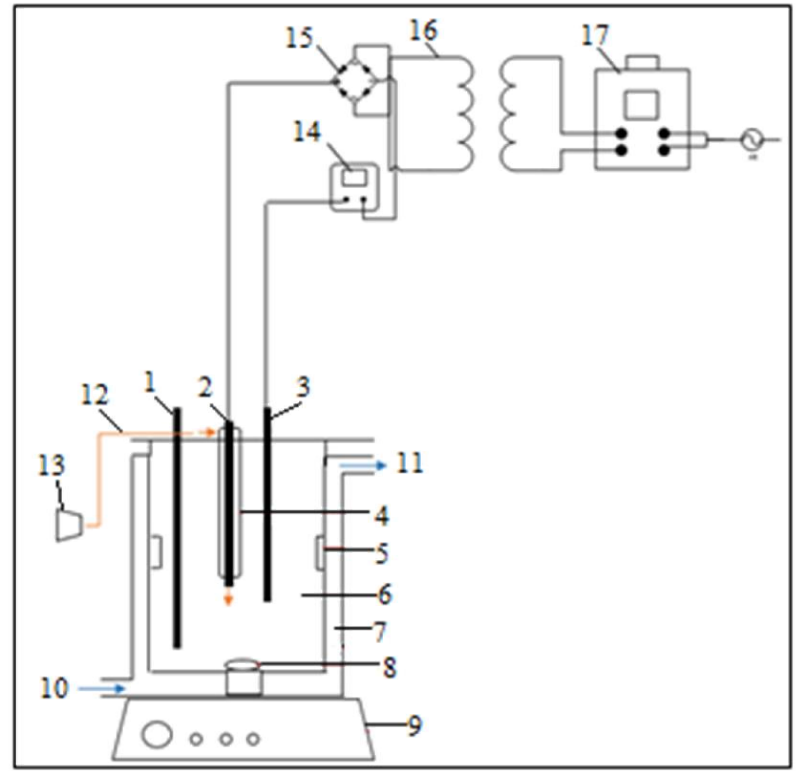

Fig. 1. Schematic view of plasma electrolysis reactor 1. Thermometer. 2. Anode. 3. Cathode. 4. Anode series with glass tube of gas injection. 5. Baffle. 6. Dye solution. 7. Cooling water. 8. Magnetic bar. 9. Magnetic stirrer. 10. Cooling water inlet. 11. Cooling water outlet. 12. Gas injection inlet. 13. Compressor. 14. Multi-meter. 15. Diode bridge. 16. Transformator. 17. Slide regulator.

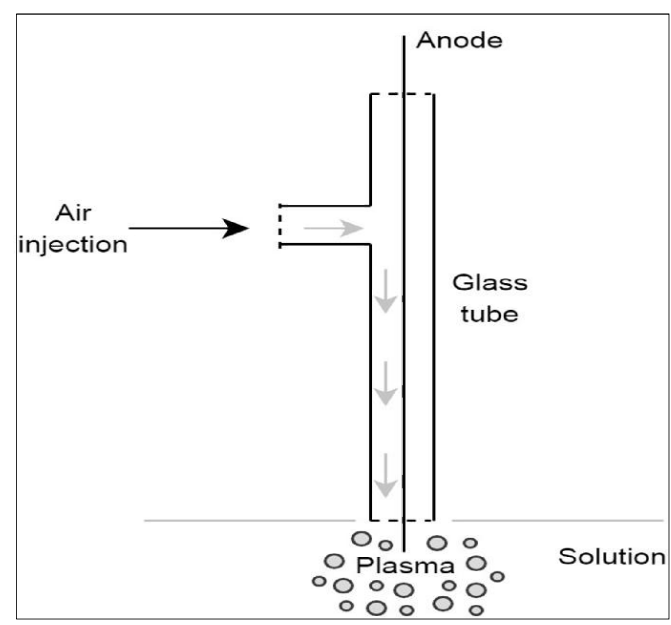

Fig. 2. Schematic view of glass tube for injection

The measurement of the $\mathrm{OH}$ radical concentration for each voltage variation, gas injection flow rate, and non-injection gas were performed by titration using $\mathrm{Na}_{2} \mathrm{SO} 0.02 \mathrm{M}$ electrolyte solution as titrant and $\mathrm{KMnO}_{4}$ $0.01 \mathrm{~N}$ solution as titer. The dye solution used was remazol red RB 133 with an initial concentration of 200 ppm. The addition of $\mathrm{Fe}^{2+}$ ions of $20 \mathrm{ppm}$ serves as a catalyst in the process of decolorizing the pollutants to decompose $\mathrm{H}_{2} \mathrm{O}_{2}$ into the $\mathrm{OH}$ radicals [6].

\section{Result and Discussion}

\subsection{Energy consumption for plasma generation}

The energy consumptions for non-air injection and air injection with flow rate variation $(0.3,0.5,2,4$, and 6$)$ $1 /$ min at each operating voltage for 30 minute process are shown in Figure 3.

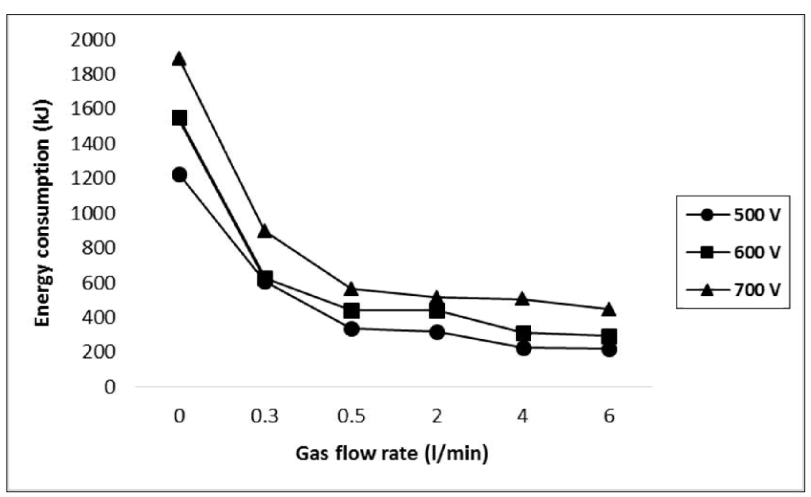

Fig. 3. Energy consumption of non gas injection and various gas flow rates at different operation voltages

The higher the operating voltage, the higher the energy required for the process. This is because the higher the operating voltage, the kinetic energy passing through the electric field is also higher and will produce heat which will produce the gas sheath in the formation of plasma [8]. In the variation of flow rate, the results showed that air injection can decrease the energy consumption significantly compared to non-gas injection (0 $1 / \mathrm{min})$ which is more than $50 \%$ for the smallest air flow rate $(0.3 \mathrm{l} / \mathrm{min})$. The figure also shows that the higher the airflow rate injected at each voltage, the lower the energy consumed in the process. The use of air injections can initiate ionization processes in plasma formation so as to reduce the amount of energy consumption required for Joule Heating during evaporation [3, 9-12]. Air injection can create bubbles and layers of gas sheaths in the solution and in areas where electrical energy dominates or around the electrodes where plasma formed [3]. The bubbles and gas sheaths formed from the injected air can lower the breakdown voltage required for the ionization process. This is due to the smaller dielectric strength of the gas compared to the liquid [2]. The required breakdown voltage in the liquid as a medium for producing plasma is much higher when compared with using air injection as additional medium. In addition, the decreased energy consumption due to air injection will reduce heat loss in the Joule Heating process so as to prevent and reduce the erosion that occurs in the electrodes where the plasma is formed[3]. It can be concluded that the use of air injection can make the process more efficient than without air injection.

\section{$3.2 \mathrm{OH}$ radicals concentration}


Figure 4 shows the concentrations of $\mathrm{OH}$ radicals formed for the flow rate variations of gas injection and non gas injection at different voltages for 30 minutes of the process.

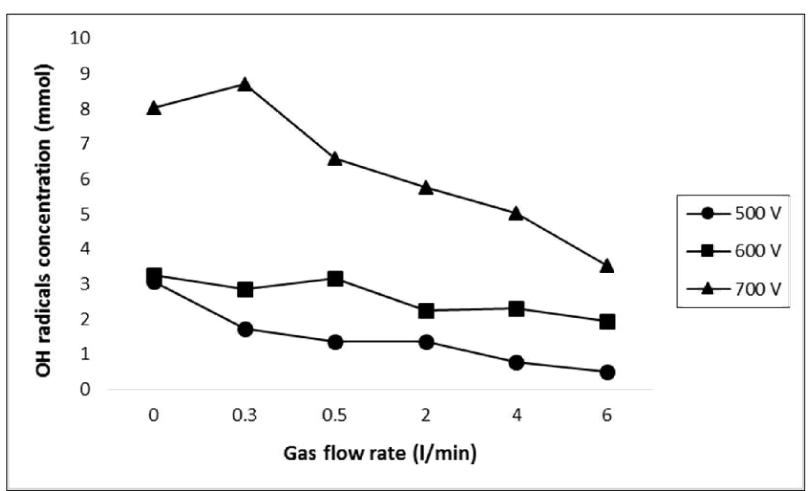

Fig. 4. OH radicals concentration of non gas injection and various gas flow rates at different operation voltages.

Figure 4 shows that in each voltage variations, the higher the air flow rate was injected, the $\mathrm{OH}$ radicals concentration tended to decrease. This is caused by the decreasing energy that can be seen from the decrease in current with increasing the flow rate of air injected. Air flow rate with direct injection method on the anode can affect the physical characteristics of the formed plasma. The higher the rate of air flow, where energy consumption will decrease, causing the formed plasma to become unstable. Plasma instability can be seen from the physical form of plasma dimmer. The plasma formed will be unstable if the flow rate of air injection is too large since the excessive production of bubbles and gas sheaths can inhibit plasma formation, therefore instability of the plasma makes its ability to produce the radical reactive species of $\mathrm{OH}$ to be lower. Plasma that has the brightest physical shape formed in the non-gas injection condition, this is due to the energy required to form the plasma is the greatest compared to the variation of gas injection at all flow rates. The Physical form of dim plasma is caused by the formation of bubbles and layers of gas sheats that can disrupt the formation and stability of plasma, so the plasma becomes unproductive in producing $\mathrm{OH}$ radicals. Increased energy will be directly proportional to the production $\mathrm{OH}$ radicals. The higher the voltage will induce an increase of the current, resulting in high kinetic energy of electrons to produce greater heat in the formation of plasma, so the $\mathrm{OH}$ radicals production will be extensive [8]. In the non-gas injection variation, the energy consumption is very large and the plasma formed is brighter and more stable, so the $\mathrm{OH}$ radicals production is greater. However, at voltages of 600 and $700 \mathrm{~V}$, the largest production of $\mathrm{OH}$ radicals comes from the gas injection variation in the smallest flow rate of $0.3 \mathrm{l} / \mathrm{min}$. This is because in the high voltage, the addition of the lower level of flow rate can effectively help in stabilizing the process of Joule Heating on the formation of plasma so as to produce greater amount of $\mathrm{OH}$ radicals.

\subsection{Decolorization of remazol red solution}

The percentage of decolorization for non-gas injection and gas injection with variations in flow rate $(0.3,0.5,2$, 4, and 6) $1 \mathrm{~min}$ at each operating voltage for 30 minute of process are shown in Table 1.

Table 1. Decolorization rate of non gas injection and various gas flow rates at different operation voltages.

\begin{tabular}{|c|c|c|c|}
\hline \multirow{2}{*}{$\begin{array}{c}\text { Gas flow rate } \\
(\mathbf{l} / \mathbf{m i n})\end{array}$} & \multicolumn{3}{|c|}{ Decolorization (\%) } \\
\cline { 2 - 4 } & $\mathbf{5 0 0} \mathbf{V}$ & $\mathbf{6 0 0} \mathbf{~ V}$ & $\mathbf{7 0 0} \mathbf{~}$ \\
\hline $\begin{array}{c}\mathbf{0} \\
\text { (non gas injected) }\end{array}$ & 86.50 & 94.66 & 97.91 \\
\hline $\mathbf{0 . 3}$ & 88.92 & 95.06 & 88.40 \\
\hline $\mathbf{0 . 5}$ & 86.51 & 97.83 & 91.96 \\
\hline $\mathbf{2}$ & 79.87 & 98.44 & 92.55 \\
\hline $\mathbf{4}$ & 74.59 & 94.18 & 99.35 \\
\hline $\mathbf{6}$ & 71.18 & 93.59 & 97.27 \\
\hline
\end{tabular}

Table 1 shows the result that plasma formation has specific behavior to the gas injection flow rate and operating voltage in the decolorization process. The trend in the percentage of decolorization is not directly proportional to the $\mathrm{OH}$ radicals production as shown in Figure 4. There is an optimum point of airflow rate at each voltage, which is the point where the percentage of decolorization reaches its maximum value before declining. From Table 1 it can be seen that in operating voltages of $500 \mathrm{~V}, 600 \mathrm{~V}$, and $700 \mathrm{~V}$, respectively has an optimum flow rate of $0.3 \mathrm{l} / \mathrm{min}, 2 \mathrm{l} / \mathrm{min}$, and $4 \mathrm{l} / \mathrm{min}$. The inconsistency of the trend with $\mathrm{OH}$ radicals shows that the decolorization process by direct injection of air into the plasma formation area depends not only on the $\mathrm{OH}$ radical as the strongest oxidant in decomposing the pollutant, but also the formation of other reactive species during the decolorization process. The injected air will form bubbles and gas sheath layers that can easily initiate ionization and excitation of more electrons, so in addition to the reducing energy consumption, it can also affect the formation of other active species other than the $\mathrm{OH}$ radicals [3, 9-12].

The nitrogen content in the injectable air can form an active species that affects the dye decolorization process [13] where the reaction equation occurs is as follows (Equation 1).

$$
\mathrm{N}_{2}+\mathrm{H}_{2} \mathrm{O}+\mathrm{O}_{2} \rightarrow \mathrm{HNO}_{3}^{-}
$$

In addition, during the air injections, some nitrate products such as $\mathrm{NO}, \mathrm{NO}_{2}^{-}$, dan $\mathrm{NO}_{3}{ }^{-}$are also formed.

Furthermore, the $\mathrm{OH}$ radicals that have formed in the plasma electrolysis process have highly reactive properties to all existing species, so it can react with oxygen contained in the injected air and produce other reactive species [14]. The equations of the reaction 
occurring between oxygen and $\mathrm{OH}$ radicals are as seen at Equation (2) - (5).

$$
\begin{aligned}
& e+O_{2} \rightarrow O \bullet+O \bullet+e \\
& \mathrm{O} .+\mathrm{H}_{2} \mathrm{O} \rightarrow \cdot \mathrm{OH}+\bullet \mathrm{OH} \\
& e+\mathrm{H}_{2} \mathrm{O} \rightarrow \mathrm{H} \bullet+\bullet \mathrm{OH}+e \\
& \mathrm{HO} \bullet+\mathrm{O}_{2} \rightarrow \mathrm{HO}_{2} \bullet+\mathrm{O} \bullet
\end{aligned}
$$

From the equations (1) and (5) it shows that the use of air injection will produce other reactive species other than the $\mathrm{OH}$ radicals, such as, $\mathrm{HO}_{2}$ radicals, $\mathrm{O}$ radicals, and $\mathrm{HNO}_{3}{ }^{-}$. The active species of $\mathrm{HO}_{2}$ radical has oxidation potential of $1.06 \mathrm{~V}$ while the oxidation potential of $\mathrm{O}$ radical is $2.42 \mathrm{~V}$ [15]. From the oxidation potential value, it can be concluded that other reactive species that formed during the air injections had great impact during the process of degradation of pollutants.

The percentage of decolorization shows that the optimum point of gas injection flow rate increase along with variation of voltage used. The operating voltage is directly proportional to the amount of current generated and the energy consumption, so that the plasma formed on different voltages has different physical and chemical characteristics, depending on the energy consumption during its formation. The larger the voltage, the greater the plasma produced, and vice versa. At lower voltages, the plasma formed was smaller, so when added with a large airflow rate, the plasma becomes unstable and incapable of converting $\mathrm{OH}$ radicals or other reactive species, therefore it takes a smaller flow rate to be able to decolorize pollutants effectively.

At higher voltages, the plasma formed is larger, the addition of small air flow rate becomes less effective, because the supply of oxygen and nitrogen in the injected air is not sufficient to produce reactive species, therefore it takes greater air flow rate to decolorize the pollutants. The plasma becomes unstable if the injected flow rate is too large for certain voltage value or if it has exceeded its optimum point, therefore the degradation rate decreases and becomes ineffective compared to the previous optimum condition.

The optimum decolorization percentages at operating voltages of $500 \mathrm{~V}, 600 \mathrm{~V}$, and $700 \mathrm{~V}$, respectively were $88.92 \%, 98.44 \%$, and $99.35 \%$ for flow rates of $0.3 \mathrm{l} / \mathrm{min}, 2 \mathrm{l} / \mathrm{min}$, and $4 \mathrm{l} / \mathrm{min}$. In non-air injection conditions, only the reactive species of $\mathrm{OH}$ radicals and $\mathrm{H}_{2} \mathrm{O}_{2}$ molecular species play roles in decolorizing the pollutant, so to achieve optimum decolourization requires enormous energy consumption by increasing the operating voltage [16-17]. However, this condition creates some disadvantages, such as higher demands of energy so that the process becomes less efficient and the anode condition is easily eroded in a very short time due to the continuous increase of the temperature from the plasma formation. Erosion occurring on the anode can affect the formation of plasma becomes more unstable because the formation area becomes thinner so it can decrease the effectiveness of the decolorization process.
Other reactive species formed during the use of air injections which contain oxygen and nitrogen gas have a smaller oxidizing ability when compared to $\mathrm{OH}$ radicals $(2.8 \mathrm{~V})$, but with an appropriate airflow rate at certain voltage, plasma can be productive in generating the reactive species in a large quantities, so when compared to non air injection, the use of air injection is considered more effective in decomposing the complex pollutants contained in the remazol red dye solution.

\section{Conclusion}

The effect of air injection flow rate on the dye decolorization process using plasma electrolysis has been evaluated. It can be concluded that the higher the air flow rate was injected, the lower the energy consumption required by the process. The lower energy consumption due to the greater air flow rate injected, causing the physical characteristics of the plasma to be smaller and dimmer, and the $\mathrm{OH}$ radicals production become decrease. However, a decrease in the number of $\mathrm{OH}$ radicals, the percentage of decolorization was found to be higher.

This research was partially funded by "Hibah Publikasi Internasional Terindeks Tugas Akhir Mahasiswa Universitas Indonesia 2018 Contract No. 2500/UN2.R3.1/HKP.05.00/ 2018" from Directorate Research and Community Service Universitas Indonesia. The authors declare no competing interests or any conflicts of financial interests.

\section{Reference}

1. J. Gao, X. Wang, Z. Hu, H. Deng, J. Hou, X. Lu, J. Kang, Plasma degradation of dyes in water with contact glow discharge electrolysis, Water Research, 37, pp 267-272, (2003).

2. M.W. Ahmed, R. Suresh, J.K. Yang, S. Choi, H.J. Lee, Effect of water conductivity on the generation of oh radicals in high frequency underwater capillary discharge, International Journal of Renewable Energy and Environmental Engineering, 04, pp 28-34, (2016).

3. Ruma, M.A. Habib, SHR. Hosseini, T. Sakugawa, H. Akiyama, Treatment of wastewater by underwater discharge in gas bubbling water, International Journal of Renewable Energy and Environmental Engineering, 03, pp 189-194, (2015).

4. R. Burlica, M.J. Kirkpatrick, W.C. Finney, R.J. Clark, B.R. Locke, Organic dye removal from aqueous solution by GlidArc discharges, Journal of Electrostatics, 62, pp 309-321, (2004).

5. O.T. Can, M. Bayramoglu, M. Kobya, Decolorization of reactive dye solutions by electrocoagulation using aluminium electrodes, Ind. Eng. Chem. Res, 42, pp 3391-3396, (2003).

6. J. Gao, X. Guo, D. MA, Wu. Yang, The role of $\mathrm{Fe}(\mathrm{II})$ in the contact glow discharge electrolysis, 
Plasma Science and Technology, 09, pp 430-435, (2007).

7. B. Pongrac, H.H. Kim, N. Negishi, Z. Machala, Influence of water conductivity on particular electrospray modes with DC corona discharge optical visualization approach, The European Physical Journal D, 68, pp 224, (2014).

8. X. Jin, X. Wang, J. Yue, Y. Cai, The effect of electrolysis constituents on contact glow discharge electrolysis, Electrochimica Acta, 56, pp 474-478, (2012).

9. S. Kanazawa, Y. Ichihashi, S. Wattanabe, S. Akamine, R. Ichiki, T. Ohkubo, T. Sato, M. Kocik, J. Mizeraczyk, Observation of liquid-gas phase dynamics from pre-breakdown to post-discharge in a single-shot underwater pulsed discharge, International Journal Plasma Environment Science and Technology, 06, pp 49-53, (2012).

10. B. Sun, M. Sato, J.S. Clements, Optical study of active species produced by a pulsed streamer corona discharge in water, Journal of Electrostatics, 39, pp 189-202, (1997).

11. K. Tachibana, Y. Takekata, Y. Mizumotom H. Motomura, M. Jinno, Analysis of pulsed discharge within single bubbles in water under synchronized conditions, Plasma Source Science Technology, 20, pp 1-12, (2011).

12. P. Baroch, V. Anita, N. Saito, O. Takai, Bipolar pulsed electrical discharge for decomposition of organic compounds in water, Journal of Electrostatics, 66, pp 294-299, (2008).

13. P.R, Gogate, A. Pandit, A review on imperative technologies for wastewater treatment 1: oxidation technologies at ambient conditions, Advanced in Environmental Research, 08, pp 501-551, (2004).

14. K. Yasuoka, K. Sato, Development of repetitive pulsed plasmas in gas bubbles for water treatment, Journal of Plasma Environmental Science and Technology, 03, pp 22-27, (2009).

15. O. Augusto, M. Sayuri, Oxygen radicals and related species, Free Radical Biomedicine, 01, (2011).

16. Ruma, N. Aoki, T. Sakugawa, H. Akiyama, M. Akiyama, Hydrogen peroxide generation by pulsed discharge in bubbling water, IEEJ Transactions on Fundamental Materials, 133, pp 636-641, (2013).

17. A.A. Joshi, B.R. Locke, P. Arce, W.C. Finney, Formation of hydroxyl radicals, hydrogen peroxide, and aqueous electrons by pulsed streamer corona discharge in aqueous solution, Journal of Hazardous Materials, 41, pp 3-30, (1995). 